\title{
Chapter 19 \\ Intervening with Realistic Mathematics \\ Education in England and the Cayman \\ Islands - The Challenge of Clashing \\ Educational Ideologies
}

\section{Paul Dickinson, Frank Eade, Steve Gough, Sue Hough and Yvette Solomon}

\begin{abstract}
In this chapter, we discuss the issue of implementing Realistic Mathematics Education (RME) in the English education system over a number of years and education sectors. We also consider the experience of one of us in the Cayman Islands, a British overseas territory with an education system that is influenced by British tradition, but is distant from many of its politically driven accountability pressures and measures. We illustrate first the challenges of developing an RME approach which is operable within the English system, highlighting the issues of student expectation, dominant didactic practices and assessment, all of which influenced what we were able to do. Second, we describe the outcomes of interventions in England at early secondary school level (age 12-14, Key Stage 3) and at General Certificate of Secondary Education (GCSE) level (normally age 15-16, Key Stage 4, but also available in post-16 education). Finally, Frank Eade describes his experience of building on our early work to develop an RME approach in the Cayman Islands. We conclude with a discussion of the lessons learned from these challenges. We argue that despite the problems we encountered there are reasons to remain optimistic about the potential of an RME approach in the English system.
\end{abstract}

Keywords Accountability pressures - Assessment - Student expectations • Progressive formalisation $\cdot$ Classroom cultures

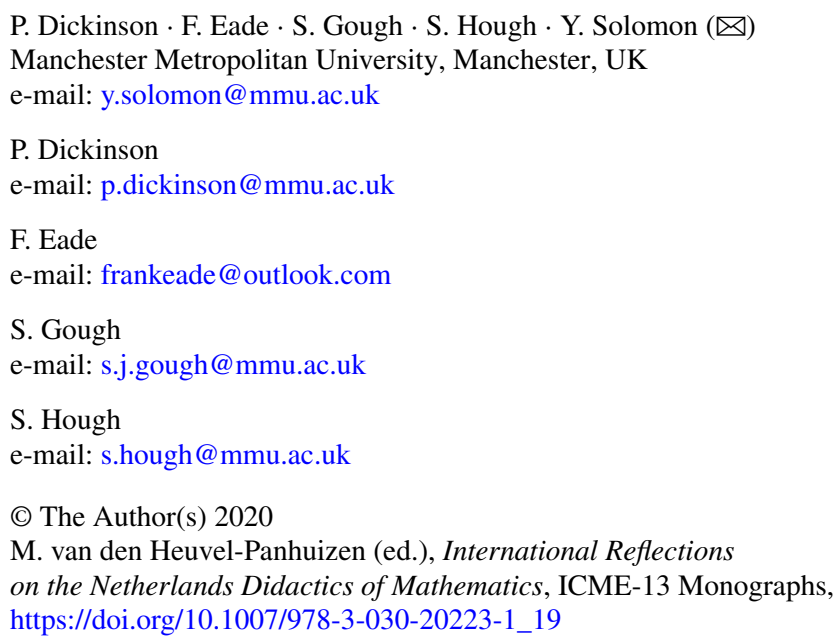




\subsection{Translating Realistic Mathematics Education into the English System: Dealing with Student Expectations, Didactic Practice and Assessment Systems}

Over the past ten years, we have led a number of projects working with teachers and their students to develop classroom approaches based on Realistic Mathematics Education (RME). Our early work included a Gatsby Foundation funded Key Stage 3 project Developing Mathematics in Context and an Esmée Fairbairn Foundation funded Key Stage 4 project Making Sense of Maths. Over 40 schools, 80 teachers and 2000 students took part. Evaluations of these projects (Dickinson \& Hough, 2012; Searle \& Barmby, 2012) comparing the progress of project students and control students have shown them to have a lasting impact in terms of teacher development and student achievement. Of particular note is the way in which these approaches have enabled students to develop methods which make sense to them, which they can apply in new situations and for which they do not need to rely on memory. This is described in Dickinson, Hough, Searle and Barmby (2011, p. 51):

Teachers noted that using RME encourages an intuitive approach, in which pupils can visualise problems, try things out for themselves, and think about different approaches to a problem, rather than having a teacher demonstrate an algorithmic technique, which pupils then practise, probably with little understanding.

More recently, we have taken an RME approach into post-16 classrooms, funded by the Nuffield Foundation. Our students have been those who had failed to gain a 'pass' grade in the public General Certificate and Secondary Education (GCSE) examinations in mathematics. This particular context has brought to the fore a number of issues which arise in implementing RME in England, in particular the impact of education policy on both teachers and students. In this section, we discuss the key features of the English context that our work has needed to address. In particular, radical differences between the Dutch and English education system and their effect on teachers' and students' experiences and expectations have presented us with considerable challenges in terms of assessment and the pace of movement towards formalisation.

\subsubsection{Classroom Cultures in England: Students' Expectations and Experiences of Mathematics}

English mathematics education traditions have had a well-documented impact on classroom cultures and on student experiences and expectations, all of which present challenges for the implementation and impact of an RME approach. In particular, student performance in public examinations is used in systems of school measurement and accountability, often leading to 'transmissionist' classroom cultures that empha- 
sise getting right answers over understanding (Noyes, Drake, Wake, \& Murphy, 2010; Wake \& Burkhardt, 2013). Many young people consequently see mathematics as a question of learning rules which lead to answers based on received wisdom and the authority of the teacher (De Corte, Op't Eynde, \& Verschaffel, 2002). It is seen as irrelevant to everyday life, and as meaningless and abstract (Boaler, 2002). The prevalent practice of grouping by ability in England often contributes to a general disaffection from mathematics for a large majority of students, in both higher and lower ability groups. In lower ability groups, they are likely to experience a reduced curriculum, which limits exposure to mathematics and the grades they can attain in public examinations at age 16 (Boaler \& Wiliam, 2001; Boaler, Wiliam, \& Brown, 2000). Students in higher ability groups do not necessarily fare any better: the high speed of coverage and competitive context reinforces students' beliefs that doing well in mathematics is a question of ability rather than effort. This situation alienates some students, particularly girls (Boaler, 1997; Solomon, 2007).

The patterns of classroom interaction that are fostered by a traditional transmissionist approach to teaching mathematics can lead students to have lower expectations of themselves as well as of mathematics. Zevenbergen (2005) argues that lower performing students' awareness of the restrictions on them in terms of curriculum and pedagogy leads them to develop a predisposition towards mathematics as negative and to behave in ways that contribute further to their reduced participation. Higher performing girls are often anxious, and many drop out of mathematics study at the post-compulsory level (Forgasz, Becker, Lee, \& Steinthorsdottir, 2010). An RMEbased approach presents not just a challenge to teachers but also to students who have become used to particular mathematics classroom cultures, which, while they might not like them, are at least predictable situations in which they have developed strategies for coping. An approach whereby students need to explain their thinking and make connections, ask questions and generally take more risks instead of simply 'learning the rules' can meet resistance (Brantlinger, 2014; Lubienski, 2007); this was particularly relevant in our more recent intervention, detailed in Sect. 19.2.2 below.

\subsubsection{Didactic Practice in England and in RME: Pressure to Move to Early Formalisation}

As highlighted above, teachers in England are very aware of the pressure to move towards formal mathematics as quickly as possible. Any contexts are quickly dropped to allow for abstraction and for the development of the desired formal methods. Progression is seen as the learning and practising of these methods, the use of them in more complicated situations (often 'bigger' numbers), and the application of the methods to answer 'contextual' questions. So, for example, in the teaching of fractions, formal notions of equivalence through 'doing the same to numerator and denominator' are quickly developed with halves and quarters and then extended to 
thirds, fifths, etcetera. The idea of a common denominator is also introduced early in the curriculum, and becomes the sole method for comparing and ordering fractions and then for addition and subtraction.

Quite early in our work with RME, on a visit to the Netherlands, we asked a group of 13-year-olds to compare $\frac{2}{3}$ and $\frac{3}{4}$ and say which was the larger. We knew from our classroom experience that this question would often prove difficult for students in England, with many saying that the fractions were equal because of the difference between the individual numbers. We were struck not just by the confidence with which the Dutch students gave a correct answer, but also by the variety of justifications that they gave. Some used an appropriate whole number (a 'mediating quantity'; Streefland, 1991) to argue that $\frac{3}{4}$ of 60 , say, was greater than $\frac{2}{3}$ of 60 ; some used a percentage or decimal argument; and a significant number compared with a whole one, arguing that $\frac{3}{4}$ needs only an extra $\frac{1}{4}$ to make it up to a whole one and is therefore the larger. Such methods would simply not have been available to U.K. students at the time.

One possible reason for this is given by looking at the lesson plans produced by the Primary Strategy launched by the Department of Education in 1999 for year 6 (11-year-old students). The first lesson for this age group begins with the question "How do you know that $\frac{2}{5}$ is more than $\frac{1}{4}$ ?" This is followed immediately with advice to the teacher to "Establish the need to change to a common denominator" and then "Discuss other examples such as comparing $\frac{1}{4}$ and $\frac{1}{3}, \frac{3}{4}$ and $\frac{7}{10}$ etcetera" and "Repeat with other examples if appropriate" (Department for Education, DfEE, 1999). While we now have a new primary curriculum (DfE, 2013), it is still dominated by formal notions of equivalence and the need to use common denominators.

In the initial stages of working with RME, it was challenging to teachers as well as students to compare fractions without using a common denominator, and the work of Streefland (1991) was critical to our development here. This gave us a framework within which we could structure lessons, and design a range of developmental questions that could be asked. It was heartening, at a later stage of the project, to see a student justify why $\frac{2}{5}$ was bigger than $\frac{1}{4}$ by picturing a restaurant where "if four people only have one pizza, it will need one new person with a whole pizza if they are to have as much as the other table. So, the $\frac{2}{5}$ have much more at the moment!"

One difficulty at this point, particularly with higher achieving students, was that they had the formal knowledge (or at least could remember the methods), but not the understanding to accompany this. So, for example, when previously asked why three pizzas shared between 4 people gave the same amount of pizza as 6 shared between 8 , these students could only justify this by referring to procedures such as "you double the numerator and double the denominator." The 'iceberg model' (Webb, Boswinkel, $\&$ Dekker, 2008) and the 'landscape of learning' (Fosnot \& Dolk, 2002) were very important to our work at this time, particularly in the development of 'milestones' on the journey towards more formal mathematics.

Influenced by RME, we began to define mathematical progress differently, with two important issues emerging. Firstly, our view of how the use of context can aid abstraction was completely changed. Before, we had always believed that we needed to take away the context in order to work on more formal mathematics. Now we came 
Fig. 19.1 Progression from 'model of' to 'model for'

\section{Progressive formalisation of models}
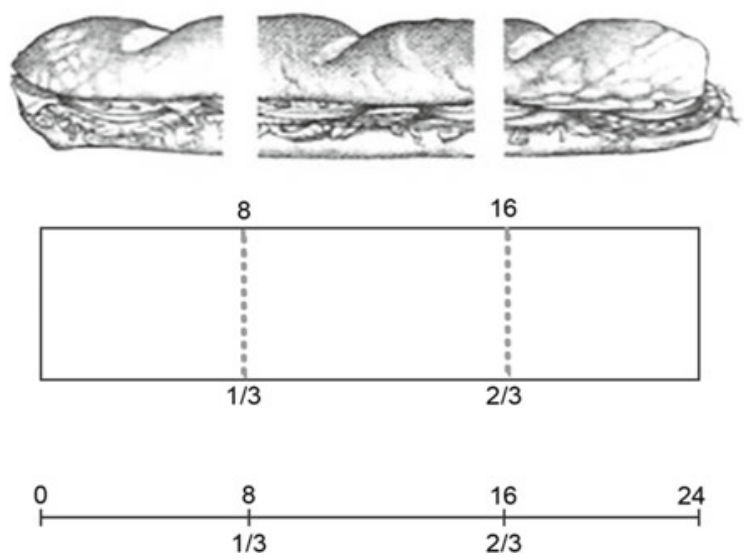

to see that adding more contexts, allowing students to see the 'sameness' of different situations, was actually a far more powerful route to abstraction. Secondly, we saw how progress could be defined through the progressive formalisation of models (Van den Heuvel-Panhuizen, 2003). In terms of fractions, this progression can be seen in Fig. 19.1, where a drawing of a sandwich eventually becomes a model for the formal comparison of fractions.

Again, the work of Streefland $(1985,1993)$ and his notion of progression from 'model of' to 'model for' was crucial here. Although as teachers we came to re-define how we saw progression, we struggled to articulate this within the U.K. curriculum. For example, the work in Figs. 19.2 and 19.3 is from two different students who have studied areas of rectangles and triangles and are then given an unfamiliar shape to work with. We would argue strongly that Student 2 in Fig. 19.3 has made more progress in understanding the notion of area, but the challenge is how to describe and validate this progress within a given assessment system: the notion of 'progressive formalisation' never seems to sit easily within the English curriculum. Despite numerous revisions, we remain locked in a teaching system which values 'little and often', with each 'little' aimed at the tip of the iceberg (Webb, Boswinkel, \& Dekker, 2008) or the 'horizon' (Fosnot, 2007), and achieving as much formality as possible. Even with recent moves to spending more time on a topic, and working with the issue of mastery (NCETM, 2014), there is little evidence of any willingness to slow down the process of formalisation. 
1. Find the area of the shape shown below.

Show carefully how you worked it out.

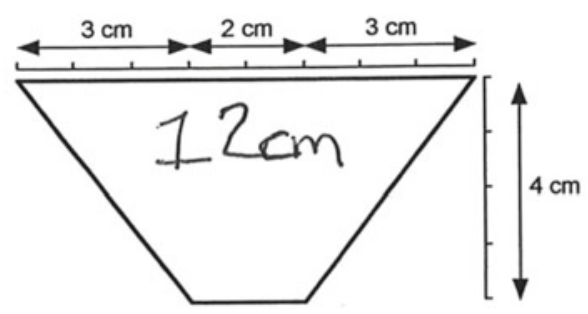

1 got this because $3 \times 2 \times 3 \times 4=48$ and the 1 divided by 4 because there a 4 numbers.

Fig. 19.2 Progression in the understanding of area (Student 1)

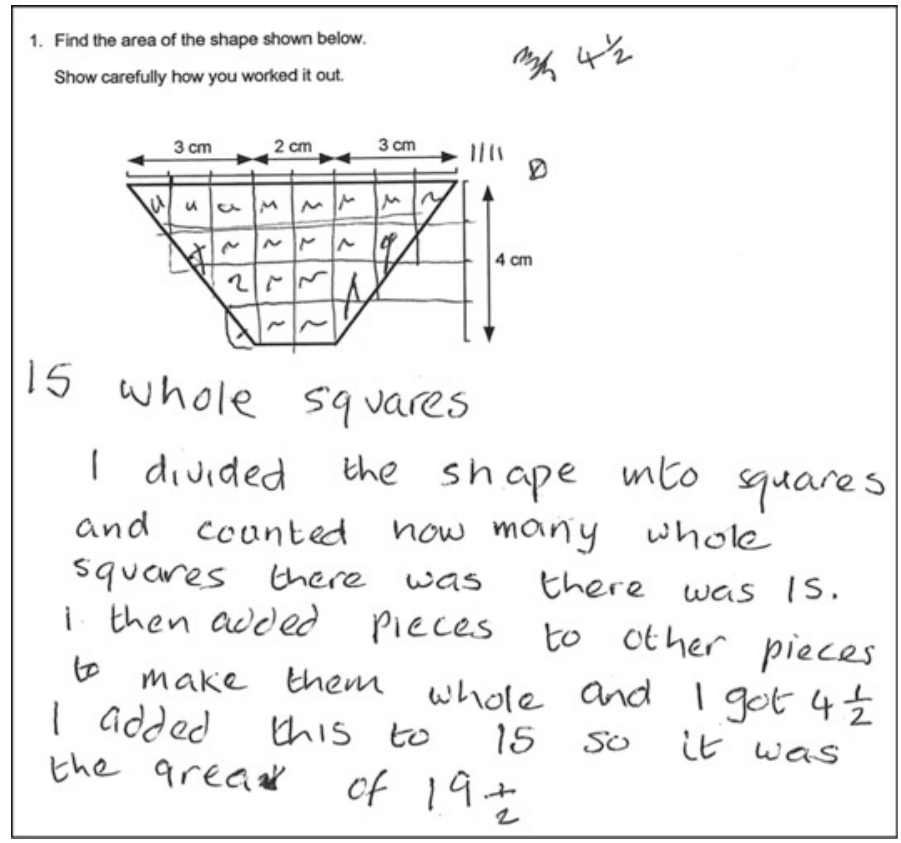

Fig. 19.3 Progression in the understanding of area (Student 2) 


\subsubsection{Assessment Systems in England and in RME: Dealing with Accountability Pressures}

In 1988, a statutory National Curriculum was introduced in England and Wales with programmes of study outlining what students should be taught and attainment targets indicating the expected level of student performance. Over a seven-year period from 1990, Standard Assessed Tests (SATs) were phased into state schools in order to measure students' levels of attainment at Key Stage 1 (age 7), Key Stage 2 (age 11) and Key Stage 3 (age 14). This was in addition to the national GCSE (General Certificate of Secondary Education) examinations for all 16 year olds at Key Stage 4. Although the statutory requirement for students to sit external examinations at Key Stage 1 and Key Stage 3 was later replaced by internal teacher assessment of the students' level, the increased frequency of national testing saw a dramatic increase in the amount of curriculum time given to teaching to the test.

Detailed prescription of what students should be taught, year by year, came with the introduction in 1999 of the Primary National Numeracy Strategy Framework followed by the Key Stage 3 National Strategy in 2001. These documents not only described what should be taught and when, but also exemplified the sorts of activities which should take place in lessons. Sample medium term plans formed the backbone of a school's scheme of work and itemised unit plans provided teachers with daily lesson objectives. The latest version of the National Strategy, launched in September 2013, has a deliberate emphasis on reducing the amount of itemised prescription. However, the practice of teachers setting specific content-loaded objectives at the start of every mathematics lesson is still prevalent.

In addition to prescribing, as never before, the detail of what should be taught, the U.K. government also set about transforming the systems by which schools were monitored. In 1992, the Office for Standards in Education (OFSTED) was established in order to ensure a rigorous and transparent process of school inspection (Elliott, 2012). The OFSTED framework for inspections has undergone many changes with increasing emphasis given to students' achievements and the quality of teaching. Expectations are that students will typically make the equivalent of two whole levels of progress from one Key Stage to the next and schools are required to evidence this. This has led to schools adopting rigorous student tracking systems with students being tested regularly in mathematics and interventions provided for those who are not making the required progress.

Increasing the amount of curriculum time devoted to teaching to the test presents a number of challenges for the implementation of an RME approach. Likewise, the U.K. practice of overtly stating content-focused objectives at the start of every lesson is contradictory to the deliberately slow route to formal mathematics that is characteristic of RME. These two clashing ideologies are discussed in detail below. 


\subsubsection{Lesson Objectives in England and in RME}

When the first trial of RME began in England in 2004, the notion of setting lesson objectives was relatively new. However, as the pressure from OFSTED with regard to students making required levels of progress increased, the practice of setting lesson objectives and sharing these with the students at the start of a lesson was seen as extremely important. This gave a way of indicating whether progress had been made during the course of one lesson towards those particular objectives. The National Strategy documentation (DfE, 2013) provides teachers with lists of objectives that students should be taught. They refer to very specific mathematical content focussing on the formal methods students need to learn. So, for example, in the geometry and measures strand of the latest version of the Key Stage 3 (age 12-14) programmes of study, it is stated that "[p]upils should be taught to derive and apply formulae to calculate and solve problems involving: perimeter and area of triangles, parallelograms and trapezia, ..." (ibid., p. 8). The Key Stage 2 programmes of study refer to "use formulae for area" and "calculate" (ibid., p. 43). Consequently, most teachers in England adopted the practice of setting lesson objectives which referred to acquisition of a formal process.

In RME, the importance of engaging with particular contexts, as well as the significance of enabling students to work with a range of informal strategies, is apparent in a different kind of lesson objective. This can be seen in Mathematics in Context (MiC) (NCRMSE \& Freudenthal Institute, 1997-1998), the textbook series developed at the University of Wisconsin in collaboration with the Freudenthal Institute. In the MiC module entitled "Reallotment" (Gravemeijer, Pligge, \& Clarke, 2003), which includes work on area, students are asked to "compare the areas of three tulip fields and determine using a variety of strategies which field has the most tulips" (p. 9). Another lesson requires that "students price tiles of different shapes and sizes by comparing their areas to the area of the $\$ 5$ tile" (p. 15). These lesson objectives make specific reference to particular contexts, and highlight that there are various ways to answer the problems. Although the second objective does direct students to the specific strategy of comparing sizes, this is not a standard formal method for finding areas.

This creates major tensions for English teachers embarking on the use of RME. Their expectations relate to students learning how to perform a mathematical procedure within the course of one or two lessons. In RME, progress to that particular procedure may involve engaging with several contexts over the course of many lessons, which could be spread over a number of years, thus enabling students to gain conceptual understanding of how the procedure works, where it might be used, and how it connects to other areas of mathematics. In all our project work supporting English teachers to trial RME, we found that many teachers were anxious about when students would be shown the formal procedure and, if unsupported, some teachers may intervene and demonstrate the formal procedure after only one contextual problem. These concerns were particularly apparent in our most recent RME project (described in Sect. 19.2.2) working with post-16 students who had not achieved a 
grade $\mathrm{C}$, where the course is designed so that the teacher and their students should re-visit as much of the GCSE syllabus as they can in nine months.

\subsubsection{The Use of Assessment in the United Kingdom and in RME}

Test-oriented teaching is an understandable consequence of placing such an important emphasis on the performance of students and their teachers and on using such thresholds to judge schools. Teaching to the test requires teachers to focus their teaching towards a particular body of knowledge, even a specific style of questioning. According to Bell (1994), it is widely practised and often results in short-term learning which soon fades away. Recent evidence from school inspections carried out in England indicates that too much lesson time is devoted to the teaching and practising of GCSE examination style questions, with an emphasis on memorising and replication of procedures at the expense of understanding (Ofsted, 2012). This effect was exacerbated when schools, in an effort to increase the number of students achieving the required standards at GCSE, embarked on the practice of entering students for examinations early and on numerous occasions.

As De Lange (1992) points out, it is the nature of the style of test questions which dictates the focus of learning in the classroom. Until recently, the style of GCSE examination questions used in England has been to place a heavy emphasis on the recall of mathematical procedures, and as a direct consequence the focus in lessons tends to be on teaching procedures rather than developing conceptual understanding. In addition, the style of questions varies very little from year to year which means that practising past examination questions would appear to be a worthwhile means of preparing students. It is therefore understandable that teachers will devote a considerable amount of time to this.

Much has been written about the role of assessment in RME. Van den HeuvelPanhuizen (2005) highlights a number of criteria which are required for problems to be considered suitable for assessment in RME. These can be summarised as follows:

- A problem must be accessible and worth solving.

- A student should be able to take ownership of a problem because it requires a decision to be made.

- A problem should enable students to demonstrate a full range of mathematical approaches from basic recall to higher order thinking.

- A problem situation should be unfamiliar so that rather than offer a standard procedure, students have an opportunity to formulate their own constructions and routes to a solution, on different levels.

- A problem situation should be imaginable so that students can apply their own knowledge and experiences and it should be suitable for mathematisation.

The contrasting style of GCSE assessment questions compared with questions designed in an RME frame can be seen in the examples illustrated in Figs. 19.4 and 19.5. 
6 Here is a list of numbers.

$\begin{array}{llllllll}11 & 8 & 11 & 14 & 11 & 15 & 13 & 14\end{array}$

(a) Find the mode.

(a). [1]

(b) Find the range.

(b). [1]

(c) Find the median.

Fig. 19.4 GCSE Question 6

20 The stem and leaf diagram shows some information about the speeds of 25 cars.

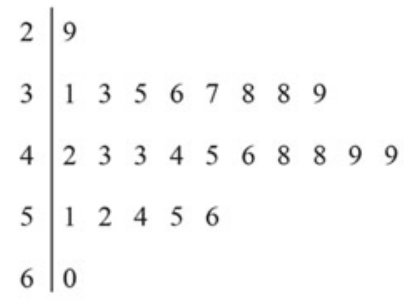

Key:

$2 \mid 9$ means 29 miles per hour

(a) How many of the 25 cars had a speed of more than 50 miles per hour?

(b) Find the median speed miles per hour

(c) Work out the range of the speeds miles per hour

Fig. 19.5 GCSE Question 20 
The first example, shown in Fig. 19.4, is not uncommon. The techniques of mode, range and median are associated with analysing data, which inevitably is a real-life context, and yet the question presents the figures as merely a set of bare numbers, completely devoid of any context or meaning. It seems likely that students might wonder why they are answering questions of this kind, other than the fact that they are on a GCSE paper. The question does not provide any opportunities for students to make decisions, to make sense of their answers, or to demonstrate higher-order thinking. Instead, the purpose of this question is to test whether students can regurgitate the steps of a series of procedures.

The second example, shown in Fig. 19.5, does refer to a real-life context, but this is not presented in such a way that students need to engage with it. A common approach to answering this question is for students to ignore the first sentence, skip onto the key words and treat the data as a set of numbers. There is no need for students to make decisions or take ownership of the problem. In many ways, this problem is really a bare number question in disguise. The strategy of highlighting the key words and numbers is a tactic promoted by teachers and revision guides alike. This in itself sends a message that the context of the question is of little or no importance.

In 2011, Hodder Education, a well-established U.K. publisher, commissioned us to write a series of textbooks based on RME principles, suitable for the U.K. market. The series, called Making Sense of Maths (Dickinson, Dudzic, Eade, Gough, \& Hough, 2012), was aimed at preparing students in the middle to low ability range for the GCSE examination. One of the challenges of writing these textbooks was to make sure that students were sufficiently prepared to answer GCSE questions of the type shown in Figs. 19.4 and 19.5, whilst staying true to the design principles of RME. Whilst we would have avoided writing questions of the type illustrated in Figs. 19.4 and 19.5, sometimes we would adapt and extend the ideas. For example, the speed camera question in Fig. 19.5 could be made much more purposeful if the question included car speed data for two different roads and a traffic surveyor who needed to decide which of the two roads was more in need of a speed camera. Students could be asked to find an average speed for each stretch of road using a method that they considered the most appropriate for this situation. They could also be asked to justify their choice of method and make recommendations to the traffic surveyor as to which road they believe warranted a speed camera. Setting up the context in this way where a person who needs to make a decision is introduced in the question provides the learner with a problem situation which is 'imaginable'; inviting the learner to select which average to use means that there are various 'routes to a solution'; and the fact that a decision is required encourages the learner to take 'ownership' of the problem (Van den Heuvel-Panhuizen, 2005). Writing questions which we considered to be purposeful, and which provided students with opportunities to make comparisons (between, say, two data sets, or between two different people's strategies) were two of the ways in which we were able to adapt traditional GCSE style questions so that they satisfied some of the criteria required for RME assessment.

The latest re-structuring of GCSEs to begin teaching in 2015 sees a greater emphasis on problem solving with the use of more open-ended questions set in real world contexts (OCR, 2014). This creates a greater need for teachers in England to teach in 
ways which develop a student's ability to genuinely solve problems, and may lead to less emphasis being placed on the teaching and regurgitation of formal mathematical procedures.

Despite the issues outlined above with regard to student expectations, pressure to meet lesson objectives and an examination system that promotes knowledge of formal mathematical procedures, there have been some successes in implementing RME in England. In the section that follows, we describe three RME trials in English classrooms, and exemplify ways in which students made considerable progress in developing a relational understanding of mathematics through sustained engagement with RME.

\subsection{RME Interventions and Outcomes in England}

\subsubsection{The Early Interventions: Success at Key Stages 3 and 4}

A number of influential reports published just after the turn of the century highlighted concerns in the teaching and learning of mathematics in the United Kingdom. In particular, the report Making Mathematics Count (Smith, 2004) recommended the increased use of applications of mathematics, and a number of research papers (Anghileri, Beishuizen, \& Van Putten, 2002; Brown, Askew, Millett, \& Rhodes, 2003; Hodgen, Küchemann, \& Brown, 2009) reported that although there had been improvements in students' end of school assessments, longer term conceptual understanding and the ability to apply mathematics remained an issue. It was against this background that our interest in RME evolved.

In 2004, the Gatsby Foundation funded Manchester Metropolitan University (MMU) to trial the RME approach using the MiC textbook series. The trial lasted three years and involved over 400 project students aged between 11 and 14 in 12 schools. Lessons in these project classes were delivered using MiC books, selected by tutors at MMU to meet the requirements of the U.K. mathematics curriculum. For the purpose of comparison, each project student was matched with a control student. Results showed that project and control students performed at approximately the same level in traditional examination questions; this was in spite of the fact that control students experienced lessons that were specifically designed to allow them to succeed with this type of question. In comparison, project students had received a diet of MiC problems that had little resemblance to the examination and yet their results matched those of their assessment-led peers. Although this alone reinforced our confidence in the RME approach, the results of our problem-solving tests were even more interesting. These tests were designed to assess students' ability to mathematise an unfamiliar problem. We found that over twice as many age-12 project students as control students in the lower quartile ability range were able to answer this type of questions successfully (36\% project, $17 \%$ control). In the middle range a smaller but still significant positive difference occurred (55\% project, $43 \%$ control), 
Fig. 19.6 Example of a question eliciting mathematical understanding

Find $1 / 1 / 2$

Do you think you have got this right? Explain why.

Table 19.1 Key stage 4 (age 14-16) results of the fractions addition question shown in Fig. 19.6

\begin{tabular}{l|l|l|l}
\hline & $\begin{array}{l}\text { Target GCSE Grade C (middle } \\
\text { ability) \% correct }\end{array}$ & $\begin{array}{l}\text { Target GCSE Grade D/E (lower } \\
\text { middle ability) \% correct }\end{array}$ & $n$ \\
\hline $\begin{array}{l}\text { Project } \\
\text { students }\end{array}$ & 83 & 57 & 50 \\
\hline $\begin{array}{l}\text { Control } \\
\text { students }\end{array}$ & 72 & 30 & 50 \\
\hline
\end{tabular}

and in the upper quartile results for project and control students were similar. There was "evidence that project pupils' approach to problem solving changed and this influenced how they understood the mathematics" (Searle \& Barmby, 2012, p. 9). What was particularly striking was the willingness of the project students to "have a go' at the problems, indicating confidence in their ability to make sense of a problem and to apply their mathematics in different contexts. These findings confirmed the need to re-define our own understanding of progress in mathematical development, while a corresponding shift in teachers' beliefs resulted in requests from project teachers for classroom materials for students aged 14-16 years.

In response, in 2007 we began producing our own resources for the 14-16 years age group, initially in collaboration with the Freudenthal Institute and then more independently, drawing on our experiences from our initial project. These materials were trialled in 16 schools and published by Hodder Education as a series of books for use with GCSE students (Dickinson et al., 2012). As the students involved in this new project were approaching their final GCSE examinations, there was a need to accelerate the learning trajectory to allow them to answer more formal, abstract questions within two years of teaching. There was also an issue of convincing students brought up on a diet of teacher exposition followed by student consolidation that what we were offering them was real mathematics. Again, our research involved project and control students, but in this instance, we focused our trial on the middle and lower middle ability range, the group of students that had benefitted most in our previous study. Their achievement in the formal GCSE examinations at the end of the trial was again broadly similar but there were remarkable differences in their ability to answer problem-solving questions. To illustrate this, we will look in detail at one of the questions (Fig. 19.6).

Although this does not immediately present itself as a problem-solving question, for the many students who had forgotten the method it required an application of their mathematical understanding, and provided many insights into their understanding of fractions. Table 19.1 displays the results for the 50 project students and 50 control students. 
The project students were able to use a range of strategies to answer the question. Their explanations often involved a drawing (usually a bar or a circle) to illustrate and make sense of the mathematics. Contexts such as cakes and pizzas were utilised to justify their solutions. Those control students who could remember the algorithm they had been taught were able to achieve the correct answer. However, those who had forgotten the method, or some part of it, were unable to engage in the question in any other way, having no mathematical resources to fall back on. This was particularly true of lower middle ability control students, half of whom gave $\frac{2}{6}$ as the answer, whereas none of the project students offered this answer. Generally, the control students justified their solution by describing their numerical method and the procedure that they had used. This question, and others like it, suggested that RME provided strategies that would be remembered for longer and were underpinned by informal and intuitive mathematical understanding. These findings resonated with comparative studies of the relative progress of British and Dutch students, for example, Anghileri et al.'s (2002) research into students solving problems involving division. We felt that, despite the challenges of implementing RME in England, continuing to develop this approach was worthwhile.

\subsubsection{Intervening in GCSE Resit Classes: Student Resistance and Success}

Following on from our interventions at Key Stage 4, our most recent project (Nuffield Foundation, 2015) has presented some of the toughest challenges for the use of an RME approach in an English education policy climate. Since September 2013, students who have not achieved an acceptable pass grade in GCSE mathematics by the age of 16 are now required to work towards this as part of a 16-19 study programme. This requirement raises multiple issues. Firstly, the short duration of post-16 GCSE resit courses (6-9 months only) means that teachers feel a particular tension between covering content and taking the time to develop understanding (Swan, 2006). Consequently, a large proportion of GCSE resit teaching focuses on examination practice, transmission teaching, and memorisation of rules and procedures. Secondly, students on GCSE resit courses are amongst the most disaffected in terms of studying mathematics; their prior experience of expected low attainment impacts on their predisposition to study and their attitudes towards, and beliefs about, mathematics (Boaler et al., 2000; Dalby, 2013). Indeed, resit examination success rates are poorlatest statistics relating to the academic years 2012-2017 show that between 2012 and 2016 an average of just $8.6 \%$ of students leaving school at age 16 without an acceptable pass in GCSE mathematics went on to achieve an acceptable grade during 16-18 education, with a rise to only 13.3\% between 2016 and 2017 (DfE, 2018).

We were interested to explore whether a slower-paced intervention based on supporting understanding through an RME approach could have a positive impact on students' achievement, understanding and engagement, and their general attitudes 
towards mathematics. Teaching number and algebra in four GCSE resit classes, we employed sustained use of context and models in order to help students imagine problems and to support the process of increasing but very gradual formalisation while retaining sense-making. Interventions in number and algebra based on this approach were trialled in four project and four parallel control classes spread across three different post-16 education sites, with a total of over 100 students. We encountered a number of difficulties in working with this group. Host teachers were not always willing to allow us our planned time, student attendance was poor, and there was wide variation in their prior achievement (some had barely missed a pass grade in the past, while others came to the course with a history of multiple failure grades). In particular, our work with algebra came under pressure due to its proximity to the GCSE examination - teachers were anxious to cover the syllabus and were reluctant to allow us to proceed at the pace we felt was necessary.

We did find small but significant gains for the project group on the number module $(F(1,93)=4.55, p=0.035$, partial eta squared $=0.047)$, and some indications of associations between participation in the project group and attitudes towards mathematics, but these did not reach significance. We also collected a variety of qualitative data (we interviewed case-study students about their experience of learning mathematics and conducted post-test videoed discussions about their work) which have enabled us to obtain a clearer picture of the impact of RME for this group. Alongside close analysis of their test scripts, these data show that, while some students gain from the RME approach, changing their overall beliefs about mathematics learning is difficult, especially within the context of education systems which put pressure on both students and teachers to learn and teach rules without meaning in order to make short-term progress. These issues are illustrated in the case of one student, Joel, who was able to gain from the RME approach, but needed more time to develop his understanding. His score in the number tests moved from $\frac{1}{17}$ to $\frac{10}{17}$. Figure 19.7a-d shows Joel's working in Questions 4 and 7. Sections b and d in this figure illustrate how he used the RME bar model productively in the post test. Question 7 in particular is considered to be quite challenging for this group.

However, in his post-test interview Joel's security with the RME modelling process came under scrutiny in discussion about his post-test solution to Question 2, illustrated in Fig. 19.8. The fact that the bar had to be divided into seven led to problems for Joel as he tried to apply his (often successful) strategy of halving to solve the problem. While his post-test answer to Question 7 shows real sense-making, his solution to Question 2 shows him dropping back into an algorithmic approach to mathematics in which he persists in applying halving, apparently without thinking about its usefulness or how the model will work. In his post-test interview, Joel needed heavy scaffolding to help him think about the problem, and like other students, he showed a tendency towards using the bar as the basis for an algorithmic strategy rather than as a model for making sense of the problem. Despite the obvious advantages of drawing diagrams that the RME approach provided him with, and which he acknowledged, Joel found it hard to move away from his previous ways of engaging with mathematics. In interview, he said: 


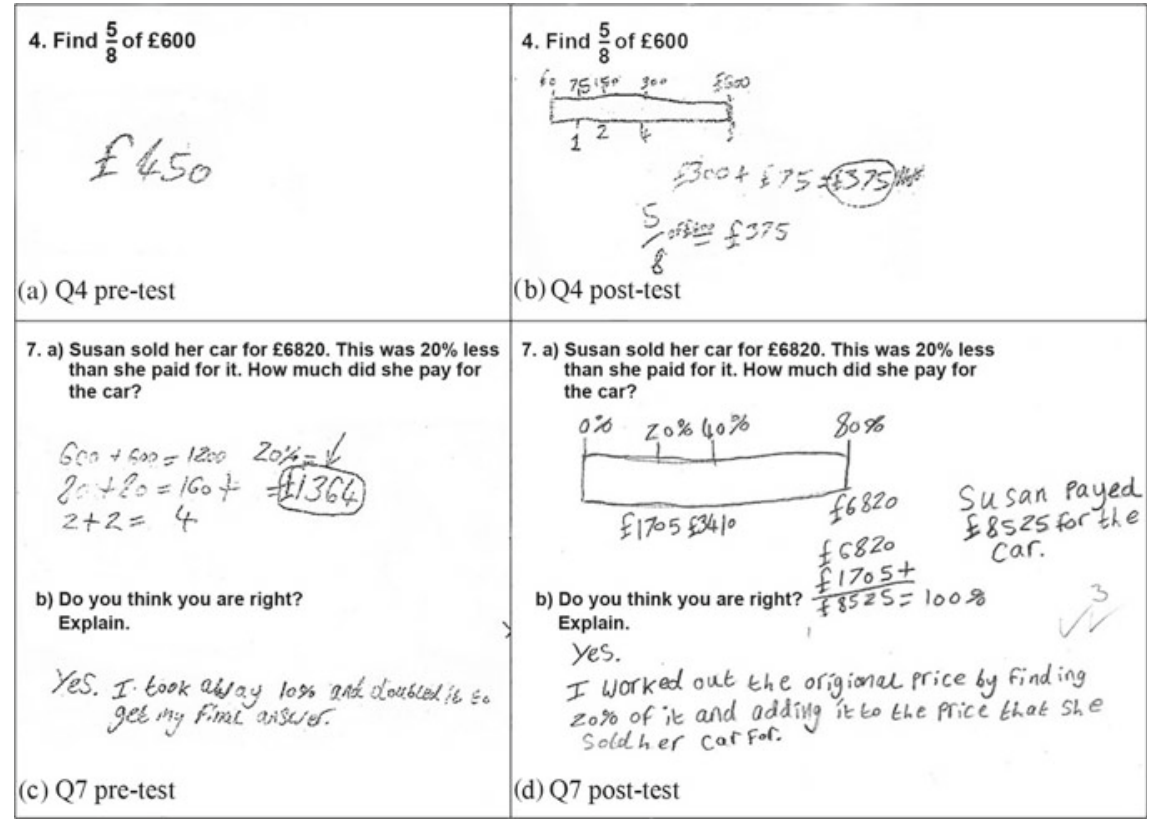

Fig. 19.7 Joel's pre- and post-test attempts to solve Question 4 and Question 7; in the post-test Joel used the bar model with halving

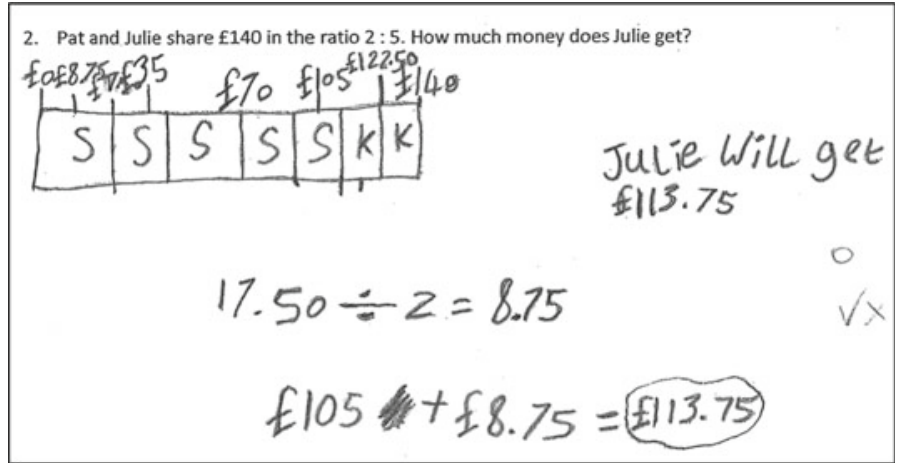

Fig. 19.8 Joel's post-test solution to Question 2 
I always kind of do it in my head. I never really put it down on paper. Although everyone says that you should because you can get extra marks.... But I've never really put my working out on paper... I find it easier just to do it in my head...

Nevertheless, Joel was amenable to using the bar. However, some students, especially those on the pass grade boundary, can be unwilling to engage with methods that they see as unnecessary and too slow, when faster learned alternatives are available. Clare prioritised speed and was reluctant to spend time representing problems diagrammatically:

I think the pictures thing, ... I just think it's wrong to do it and the other people in the class, they try and explain it. It just confuses me, because I did it. I think my way is an easier way, because I just go straight to it. ... I only find it confusing when the rest explain it and they try and get to the answer and then they'll be finding half and they have to add another one when they could just do a division and then it would give their answer.

Joel and Clare were not untypical. The RME approach provided students with strategies that they could and would use, but the legacy of their previous experience of learning mathematics presented particular problems in terms of (1) their tendency to understand the RME approach as 'just another (algorithmic) method', and (2) their resistance to, or lack of belief in, sense-making in mathematics. These issues underline the importance of moving slowly towards formalisation, and of maximising opportunities for visualisation. While these requirements provide the greatest possibility for success, they also increase the amount of class time required, and the possibility of resistance from students (and even teachers) who may be unwilling to engage with methods that they see as unnecessary and too slow, instead of faster rote-learned alternatives. The 'risks' of investing in a slower-paced didactical trajectory which emphasises understanding and engagement (and perhaps higher grades) are high. One host teacher commented on the dilemmas that giving the team time to teach the RME approach created:

With every other group I am three or four weeks ahead of [the RME one] and where am I going to squeeze in this and this and this? But you're right about the underlying understanding being really really important, so I'm pulled two ways. ... I really like what you do and buy into it, and the other side of me is saying "damn, with this group I've still got to cover this, this and this, and when am I going to do it?", because when I start teaching again I've still got things on the scheme of work to do...

\subsection{Moving to Another Education System: Taking Lessons Learned in England to the Cayman Islands}

In September 2011, Frank Eade moved from higher education in England to become a mathematics adviser in the Cayman Islands. The Cayman Islands adopted the English National Curriculum in 2008, uses the OFSTED framework for inspections and uses a primary mathematics textbook that is very popular in England. In what follows, Frank writes about his experiences of introducing an RME-based approach at primary and secondary education levels. 


\subsubsection{Primary Education}

Initial observations indicated that teachers taught very formally and struggled to cope with students' difficulties. Students were expected to learn rules given to them by the teachers, and many fell increasingly behind and participated little in lessons. Consequently, they constantly asked for help, afraid to take any mathematical risks or to use their intuitions. It also became clear that even relatively able students struggled to relate money to number, with little understanding of how money worked. For example, in a lesson with 9-year-olds using 25 cent coins lined up in groups of four to represent a dollar, the class struggled to use the coins to represent $\$ 1.25$. It became clear that teachers rarely used imagery to support mathematical development and, perhaps because of this, students had very poor number sense. In one lesson with students aged 10 years, a teacher was attempting to teach subtraction by adding on and addition by compensation. For example, he wanted the students to solve $136+$ 195 by thinking of 195 as close to 200 . The students struggled with the problems. When I drew a number line with 0 and 200 marked on it and asked them to indicate where they thought 195 was, they tended to place it somewhere close to the middle. So, two major initiatives in Cayman were to utilise models and imagery in lessons and to get teachers to simulate the use of money in the classroom and to encourage parents to take children to the shops - not a common practice, as it turned out-and get them used to using money.

Because of the high number of struggling students, we introduced the Mathematics Recovery training programme (Wright, Stranger, Stafford, \& Martland, 2014), which makes extensive use of images such as 10-frames, the Rekenrek (arithmetic rack), the 100-bead bar and arrays to support mathematical development, but little use of contexts. Through gradual but sustained exposure to these images as well as the empty number line, a group of teachers who were training to become leaders in primary mathematics developed their understanding of N10, N10C, A10 and 1010 (Beishuizen, 1997) and started to use these. Although it took time, they began to use contexts as a means of entry to mathematics and some did their best to use context throughout. We began to develop study units to help teachers with classroom ideas but also to support them in understanding how the mathematics would develop. Where teachers' thinking and experience related to the teaching and application of rules, change required considerable effort not only in developing activities, but also

\footnotetext{
${ }^{1} \mathrm{~N} 10=$ The first number is kept whole, the second number is split into tens and units and the tens of the second number are added to the first number followed by the units.

$\mathrm{N} 10 \mathrm{C}=$ The first number is kept whole, the second number is rounded up to a multiple of ten and this number is added to the first number followed by an adjustment or compensation for the rounding.

$\mathrm{A} 10=$ The first number that is kept whole, the second number is split so that a number of its units are added to the first number to arrive at a multiple of ten and then the remainder is added to the first number.

$1010=$ Both numbers are split into tens and units and then the tens are added together, then the units, then the combined tens and units are added together.
} 
Fig. 19.9 Explanation of how the subtraction $91-37$ is solved

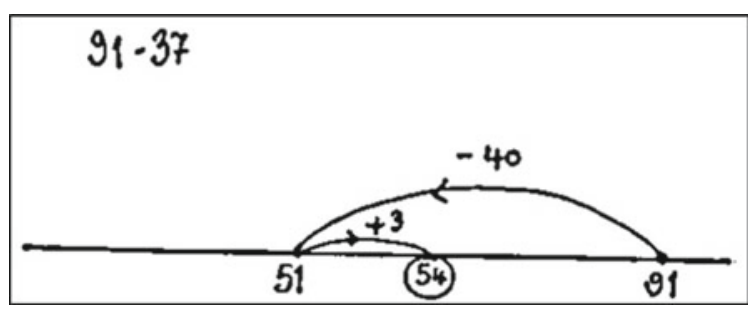

in developing the 'big picture' and a sense of how the mathematics developed over time.

In my first year in Cayman, in 2011, I tested students to find out how they solved number problems. Given $154+49$, the facility for Year 4 was $45 \%$ and for Year 6 was $78 \%$. No student solved the problem by adding 50 and subtracting 1 . Following the interventions described above, facilities in 2013 increased to 70 and $85 \%$ respectively. However, although the number of students using compensation increased, it was still very low. In another problem, shown in Fig. 19.9, students had to explain how 91-37 was solved. In 2011, only $16 \%$ of Year 6 students, the vast majority of these being high attaining, could provide a reasonable explanation of how it was solved and understood the use of the number line. In 2013, the facility for year 6 was now $46 \%$. Considering the responses to $154+49$, this does suggest that students become aware of a strategy before they actually use it strategically.

Another question in 2015 asked students to solve 315-180 and about 20\% used an empty number line with some also using it to confirm the accuracy of their formal answer. So, change was taking place, albeit slowly. This change was further evidenced by work on division, where between 2011 and 2013 the proportion of Year 6 students successfully answering a standard problem rose from 31 to $61 \%$. There was also evidence of more students using less formal methods such as 'chunking' (Anghileri $\&$ Beishuizen, 1998). Figure 19.10, showing some of the strategies used by Year 5 to solve the problem $222 \div 3$, evidences further the changes that we began to see. Students were starting to make strategic decisions about how to solve problems rather than just following a procedure provided by the teacher.

\subsubsection{Secondary Education}

The position in secondary was very similar to primary in that teachers taught the syllabus formally with little regard to whether students grasped the ideas or not. Because of a substantial private school sector of over $30 \%$, the ability range in state schools is skewed towards the middle and lower end. The standardised assessments, however, demonstrated very clearly that students were not making the gains that they should be and, in particular, the lowest achieving students were falling rapidly behind. 

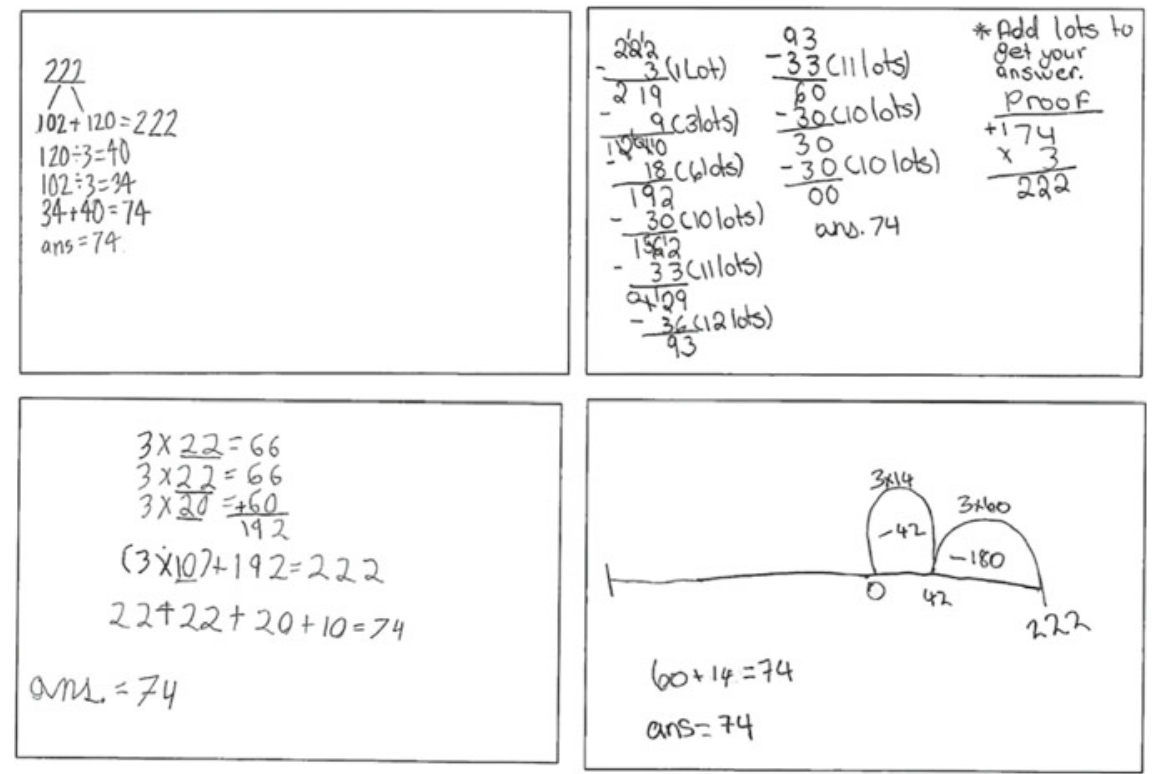

Fig. 19.10 Year 5 students' strategies for the division problem $222 \div 3$

Building on the intervention in primary schools, I tried to initiate change by providing activities for teachers to use in the classroom. Informal activities based around Cayman were introduced (see Fig. 19.11) and generally teachers warmed to the idea that working more informally was worth exploring.

Although the teachers used these activities and students really seemed to enjoy the lessons, teachers would usually revert to traditional teaching unless I provided the activities, and clearly this was not sustainable. As an alternative, teachers began to trial some MiC textbooks (Abels, Burrill, \& Wijers, 2010) with lower and middle Year 7 classes, with a particular focus on fractions, decimals and percentages. As always, some teachers were enthusiastic about the possibilities, but others agreed with some reluctance. It was clear that we needed a rigorous approach to evaluation, so among other things we developed a test to be taken in 2014 by all Year 7 students who had no MiC experiences and in 2015 by two groups (Group 2 and Group 3) who had experienced $\mathrm{MiC}$ and one group (Group 1) who had not.

The teachers were provided with a number of professional development sessions in preparation for using the materials. I met with them once every two weeks during implementation to discuss progress, and also observed lessons weekly. Table 19.2 summarises the outcomes.

It can be seen that there are only minor changes in the Group 1 (control group) scores but major gains for the Groups 2 and 3. In addition, these students also made major gains in the standardised tests used in Cayman, making close to two years gain in the year when normally they would be struggling to make a year's gain. A 


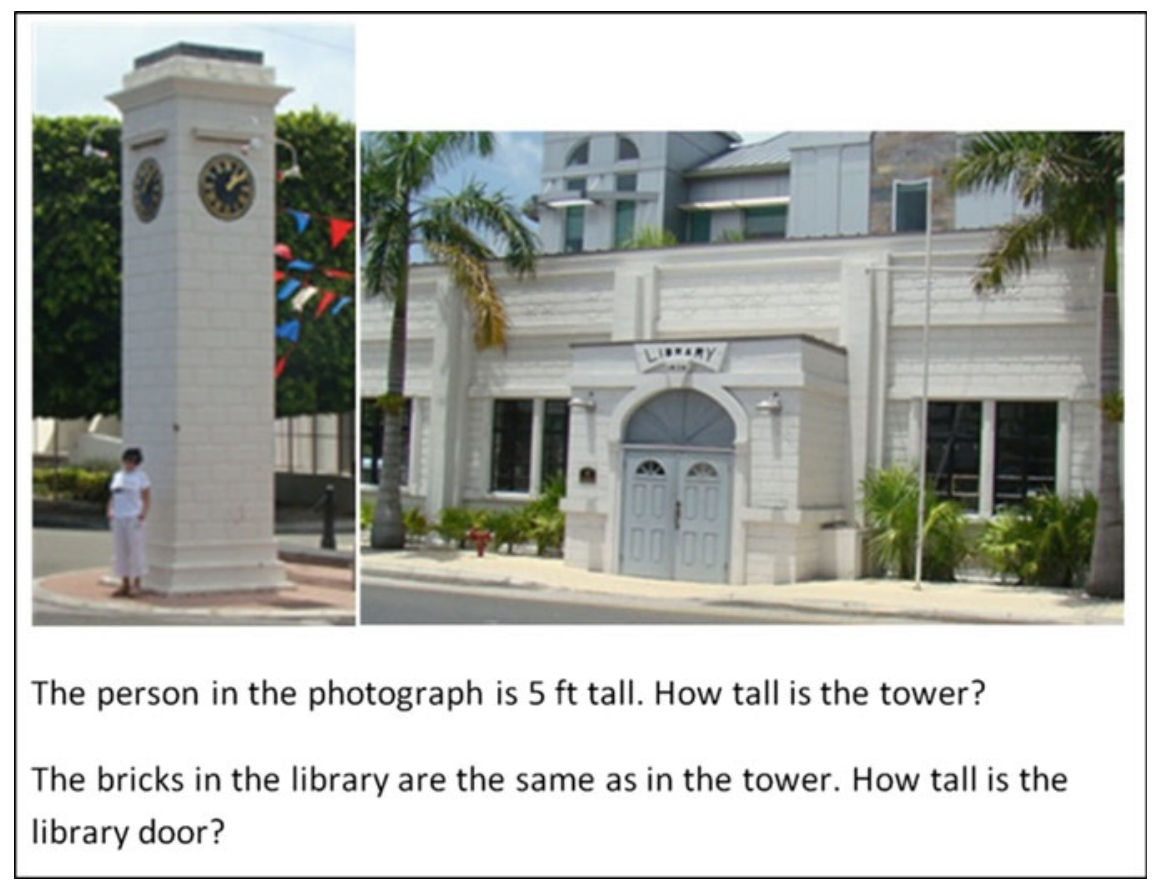

Fig. 19.11 Example of Cayman-based context problem

Table 19.2 Outcomes of the MiC intervention

\begin{tabular}{|c|c|c|c|c|c|c|}
\hline \multirow[t]{3}{*}{ Question } & \multicolumn{6}{|c|}{$\%$ correct } \\
\hline & \multicolumn{2}{|c|}{ Group 1} & \multicolumn{2}{|c|}{ Group 2} & \multicolumn{2}{|c|}{ Group 3} \\
\hline & 2014 & 2015 & 2014 & 2015 & 2014 & 2015 \\
\hline 1 & 38 & 41 & 0 & 42 & 0 & 9 \\
\hline 2 & 30 & 34 & 5 & 8 & 0 & 7 \\
\hline 3 & 57 & 67 & 29 & 49 & 18 & 33 \\
\hline 4 & 43 & 47 & 5 & 19 & 0 & 5 \\
\hline 5 & 80 & 81 & 42 & 64 & 23 & 54 \\
\hline 6 & 47 & 55 & 11 & 8 & 5 & 12 \\
\hline 7 & 70 & 60 & 24 & 32 & 13 & 7 \\
\hline 8 & 35 & 26 & 13 & 28 & 3 & 10 \\
\hline 9 & 52 & 49 & 4 & 21 & 0 & 5 \\
\hline 10 & 55 & 70 & 35 & 45 & 5 & 40 \\
\hline 11 & 13 & 11 & 2 & 4 & 0 & 2 \\
\hline 12 & 17 & 11 & 2 & 4 & 0 & 0 \\
\hline 13 & 32 & 29 & 4 & 15 & 3 & 7 \\
\hline Mean (\%) & 44 & 45 & 14 & 26 & 5 & 15 \\
\hline
\end{tabular}




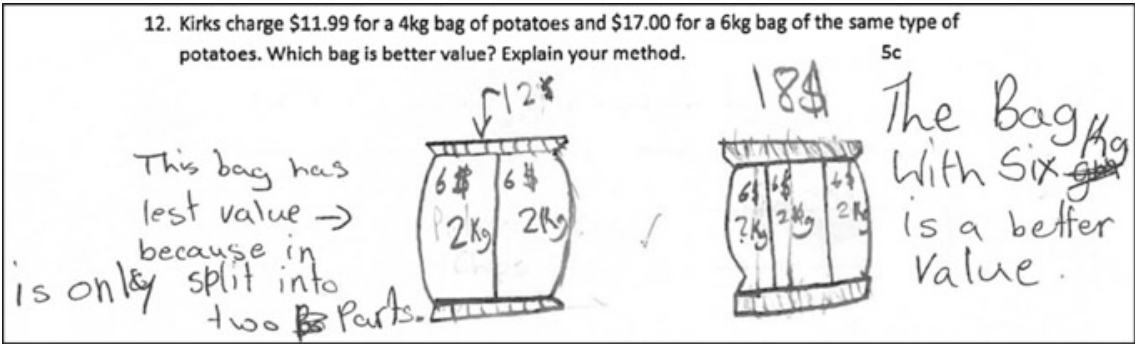

Fig. 19.12 A solution by a Group 3 student

11. Mary got 25 out of 75 in her maths test. George got 15 out of 40 .

Who did best? Explain your reasoning

George did best because it.
you adsed 15 by 15 you would
get 30 but it you adfer
10 more you would get 40 . For Mary
you have to adf 253 times.

Fig. 19.13 A solution by a Group 2 student

feature of the answers given by Groups 2 and 3 was the range of solution strategies in evidence, and the confidence with which students offered such strategies. Two of the most striking of these are given in Figs. 19.12 and 19.13.

In interviews and questionnaires, students were very positive about the experience and wanted to continue using $\mathrm{MiC}$ in Year 8. The teachers have agreed to continue using the materials in Year 8 and also to trial some algebra materials with higher ability groups in Year 7. The teachers also indicated that they were using the contexts with other year groups, adopting more interactive approaches and being more inclined to use models to support problem solving rather than focusing on formal algorithms.

Observations, however, have also highlighted a number of challenges that need to be worked on in the coming year, and which resonate with the experience of the teachers in England when first working with RME:

- Teachers want to continue with a problem until all understand, and feel uncomfortable in moving on. 
- Teachers tend to believe that when students solve a problem in context, then they understand the associated content; later, in subsequent lessons teachers realise that the skills do not transfer.

- Teachers tend to spend too long in whole class mode rather than letting students solve problems in pairs or groups first. Moving in and out of group work seems to collide with the normal practice of whole class teaching followed by exercises.

- Teachers want to formalise the content rather than allowing students a more gradual journey to formal mathematics.

For both primary and secondary education, there have been some major shifts both in the teaching and in teachers' more subtle understanding of mathematical development. However, there is still a long way to go and there is still a danger that, if the political/educational climate changes, then it would be very easy to destroy the fragile advances that have been made.

\subsection{Conclusions and Implications}

This chapter has outlined a number of initiatives aimed at implementing RME in an English system. It was clear from the outset that there would be barriers to these initiatives, and that the main principles of RME were significantly different from dominant didactic practices. In addition, these practices, along with student expectations, were often the result of external pressures such as an increasingly frequent external assessment pattern and a rigorous inspection regime. In particular, the notion of progressive formalisation, essentially for many students the slowing down of the move to formal mathematics, proved difficult to adopt. So, while teachers (and students) were enthusiastic about trialling RME, embracing it fully proved too much of a challenge for many schools.

Results, however, showed that classes who did work with RME materials produced sizeable gains, both in problem solving and in examinations. This has led teachers to continue to try to adapt RME principles to the English setting. So, while we cannot claim that RME has been implemented fully in schools, it is clear that many of the principles have been. The mathematics departments we have worked with are now far more likely to use models such as the ratio table and the empty number line, to use contexts throughout a topic, and to invoke visualisations and imagery in their lessons. There is also currently a move in schools to spend more time on topics before moving on to the next one; this does at least open up the possibility of delaying the journey to more formal mathematics, and embracing progressive formalisation. While some of the challenges we face are inevitably unique to England, others are more general issues faced by anyone attempting to develop a new approach in the classroom. Hence, when one of our colleagues attempted to develop RME in the Cayman Islands, many of the issues encountered were of a similar nature to those met in England. Those of us involved in these projects remain committed to the principles of RME, and believe that the results from the projects justify this commitment. The challenge remains as 
to how to continue to develop these principles within the constraints of our education policies and frameworks.

\section{References}

Abels, M., Burrill, G., \& Wijers, M. (2010). Mathematics in context. Key to success. Level 1. Teacher's guide . Chicago, IL: Encyclopedia Britannica, Inc.

Anghileri, J., \& Beishuizen, M. (1998). Counting, chunking and division algorithm. Mathematics in School, 27, 2-5.

Anghileri, J., Beishuizen, M., \& Van Putten, K. (2002). From informal strategies to structured procedures: Mind the gap. Educational Studies in Mathematics, 49, 149-170.

Bell, A. W. (1994). Teaching for the test. In M. Selinger (Ed.), Teaching mathematics. London, UK: Routledge.

Beishuizen, M. (1997). Two types of mental arithmetic and the empty number line. Informal Proceedings BSRLM [British Society for Research in the Learning of Mathematics], 17(1\&2), 18-22.

Boaler, J. (1997). When even the winners are losers: Evaluating the experiences of 'top set' students. Journal of Curriculum Studies, 29(2), 65-182.

Boaler, J. (2002). Experiencing school mathematics: Traditional and reform approaches to teaching. Mahwah, NJ: Lawrence Erlbaum.

Boaler, J., \& Wiliam, D. (2001). "We've still got to learn!” Students' perspectives on ability grouping and mathematics achievement. In P. Gates (Ed.), Issues in mathematics teaching. London, UK: Routledge Falmer.

Boaler, J., Wiliam, D., \& Brown, M. (2000). Students' experiences of ability grouping-disaffection, polarisation and the construction of failure. British Educational Research Journal, 26(5), 631648.

Brantlinger, A. (2014). Critical mathematics discourse in a high school classroom: examining patterns of student engagement and resistance. Educational Studies in Mathematics, 85(2), 201-220.

Brown, M., Askew, M., Millett, A., \& Rhodes, V. (2003). The key role of educational research in the development and evaluation of the National Numeracy Strategy. British Educational Research Journal, 2, 655-672.

Dalby, D. (2013). An alternative destination for post-16 mathematics: Views from the perspective of vocational students. In C. Smith (Ed.), Proceedings of the British Society for Research into Learning Mathematics (BSRLM) (Vol. 33, Issue 3, pp. 13-18).

De Corte, E., Op't Eynde, P., \& Verschaffel, L. (2002). "Knowing what to believe": The relevance of students' mathematical beliefs for mathematics education. In B. Hofer \& P. Pintrich (Eds.), Personal epistemology: The psychology of beliefs about knowledge and knowing (pp. 297-320). Mahwah, NJ: Lawrence Erlbaum.

De Lange, J. (1992). Critical factors for real changes in mathematics learning. In G. C. Leder (Ed.), Assessment and learning of mathematics (pp. 305-329). Hawthorn, Australia: Australian Council for Educational Research.

DfE. (2013). National curriculum in England: Mathematics programmes of study. https://www. gov.uk/government/publications/national-curriculum-in-england-mathematics-programmes-ofstudy. Accessed October 20, 2015.

DfE. (2018). A level and other 16 to 18 results: 2016 to 2017 (revised) National Tables SFR03/2018. https://www.gov.uk/government/statistics/a-level-and-other-16-to-18-results2016-to-2017-revised. Accessed July 31, 2018.

DfEE. (1999). The National numeracy strategy framework for teaching mathematics from reception to year 6. London: DfEE.

Dickinson, P., Dudzic, S., Eade, F., Gough, S., \& Hough, S. (2012). Making sense of maths. London, UK: Hodder Education. 
Dickinson, P., \& Hough, S. (2012). Using realistic mathematics education in UK classrooms. http:// www.mei.org.uk/files/pdf/rme_impact_booklet.pdf.

Dickinson, P., Hough, S., Searle, J., \& Barmby, P. (2011). Evaluating the impact of a Realistic Mathematics Education project in secondary schools. Proceedings of the British Society for Research into Learning Mathematics (BSRLM), 31(3), 47-52.

Elliott, A. (2012). Twenty years inspecting English schools-Ofsted 1992-2012. RISE Review, November. London, UK: RISE.

Forgasz, H., Becker, J. R., Lee, K.-H., \& Steinthorsdottir, O. (Eds.). (2010). International perspectives on gender and mathematics education. Charlotte, NC: Information Age.

Fosnot, C. T. (2007). Contexts for learning mathematics. Portsmouth, NH: Heinemann.

Fosnot, C. T., \& Dolk, M. (2002). Young mathematicians at work: Constructing fractions, decimals, and percents. Portsmouth, NH: Heinemann.

Gravemeijer, K., Pligge, M. A., \& Clarke, B. (2003). Reallotment. In National Center for Research in Mathematical Sciences Education \& Freudenthal Institute (Eds.), Mathematics in context. Chicago, IL: Encyclopaedia Britannica.

Hodgen, J., Küchemann, D., \& Brown, M. (2009). Secondary students' understanding of mathematics 30 years on. Conference presentation at the British Educational Research Association Conference, September 2-5.

Lubienski, S. T. (2007). Research, reform, and equity in U.S. mathematics education. In N. S. Nasir \& P. Cobb (Eds.), Improving access to mathematics (pp. 10-23). New York, NY: Teachers College Press.

National Centre for Excellence in the Teaching of Mathematics (NCETM). (2014). Mastery approaches to mathematics and the new national curriculum. https://www.ncetm.org.uk/public/ files/19990433/Developing_mastery_in_mathematics_october_2014.pdf.

National Center for Research in Mathematical Sciences Education (NCRMSE) \& Freudenthal Institute. (1997-1998). Mathematics in context: A connected curriculum for grades 5-8 . Chicago, IL: Encyclopaedia Britannica Educational Corporation.

Noyes, A., Drake, P., Wake, G., \& Murphy, R. (2010). Evaluating mathematics pathways. Research Report DFE-RR143. London, UK: Department for Education.

Nuffield Foundation. (2015). Achievement and attitudes in GCSE Resit Classes Project. http://www. nuffieldfoundation.org/achievement-and-attitudes-gcse-mathematics-resit-classes.

OCR (2014). GCSE (9-1) Mathematics. www.ocr.org.uk/gcsemaths.

Ofsted (2012). Mathematics. www.ofsted.gov.uk/resources/110159.

Searle, J., \& Barmby, P. (2012). Evaluation report on the Realistic Mathematics Education pilot project at Manchester Metropolitan University. Durham, UK: Centre for Evaluation and Monitoring (CEM), Durham University. http://www.mei.org.uk/files/pdf/RME_Evaluation_final_report. pdf.

Solomon, Y. (2007). Experiencing mathematics classes: How ability grouping conflicts with the development of participative identities. International Journal of Educational Research, 46(1-2), 8-19.

Smith, A. (2004). Making mathematics count: The report of Professor Adrian Smith's inquiry into post-14 mathematics education. London, UK: The Stationery Office.

Streefland, L. (1991). Fractions in realistic mathematics education. Dordrecht, the Netherlands: Kluwer Academic Publishers.

Streefland, L. (1985). Wiskunde als activiteit en de realiteit als bron [Mathematics as an activity and reality as a source]. Nieuwe Wiskrant, 5(1), 60-67.

Streefland, L. (1993). The design of a mathematics course. A theoretical reflection. Educational Studies in Mathematics, 25(1-2), 109-135.

Swan, M. (2006). Collaborative learning in mathematics: A challenge to our beliefs and practices. Leicester, UK: NIACE.

Van den Heuvel-Panhuizen, M. (2003). The didactical use of models in Realistic Mathematics Education: An example from a longitudinal trajectory on percentage. Educational Studies in Mathematics, 54, 9-35. 
Van den Heuvel-Panhuizen, M. (2005). The role of contexts in assessment problems in mathematics. For the Learning of Mathematics, 25(2), 2-23.

Wake, G. D., \& Burkhardt, T. H. (2013). Understanding the European policy landscape and its impact on change in mathematics and science pedagogies. ZDM Mathematics Education, 45(6), 851-861.

Webb, D., Boswinkel, N., \& Dekker, T. (2008). Beneath the tip of the iceberg: Using representations to support student understanding. Mathematics Teaching in the Middle School, 14(2), 110-113.

Wright, R., Stanger, G., Stafford, A. K., \& Martland, J. (2014). Teaching number in the classroom with 4-8 year olds. London, UK: Sage Publications.

Zevenbergen, R. (2005). The construction of a mathematical habitus: Implications of ability grouping in the middle years. Journal of Curriculum Studies, 37(5), 607-619.

Open Access This chapter is distributed under the terms of the Creative Commons Attribution 4.0 International License (http://creativecommons.org/licenses/by/4.0/), which permits use, duplication, adaptation, distribution and reproduction in any medium or format, as long as you give appropriate credit to the original author(s) and the source, a link is provided to the Creative Commons license and any changes made are indicated.

The images or other third party material in this chapter are included in the work's Creative Commons license, unless indicated otherwise in the credit line; if such material is not included in the work's Creative Commons license and the respective action is not permitted by statutory regulation, users will need to obtain permission from the license holder to duplicate, adapt or reproduce the material.

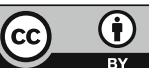

